\title{
A fase de preparação no processo de design de um produto médico-hospitalar
}

\section{The preparation phase in the design process of a medical product}

\author{
Uda Flavia Souza Fialho ${ }^{1}$ \\ Cleone Ferreira de Souza ${ }^{2}$ \\ Andreia Bordini de Brito ${ }^{3}$ \\ José Fialho de Oliveira Júnior ${ }^{4}$
}




\section{Resumo}

Este estudo apresenta a fase de preparação do projeto de um coletor de urina sistema fechado para leito, cuja função é armazenar urina de pacientes situados em Unidades de Terapia Intensiva e Centros Cirúrgicos. O objetivo foi levantar e analisar informações acerca do usuário e do produto para definir os requisitos do projeto. Foi realizada uma pesquisa no contexto de uso do coletor, pautada na observação e na conversação com os operadores, na qual foi possível observar como ocorre o manuseio do produto e realizar entrevistas informais para obter informações complementares. O resultado apresenta os requisitos do projeto para as fases posteriores do desenvolvimento do produto.

Palavras-chave: Projeto de produto, Abordagem etnográfica, Análise, Requisitos de projeto.

\section{Abstract}

This paper presents the project preparation phase of a closed system urine collector for hospital bed, whose function is to store urine of patients located in Intensive Care Units and Surgical Centers. The purpose was to gather information about the user and the product and analyse them in order to define the project requirements. A research in the context of the use of the collector was achieved, based on observation and conversation with the operators, in which it was possible to observe how the product is handled, and to conduct informal interviews to obtain complementary information. The result presents the project requirements for the later stages of product development.

Key-words: Product design, Ethnographic approach, Analysis, Project requirements.

\footnotetext{
${ }^{1}$ Doutoranda em Design, UFRGS (udaflavia@gmail.com)

${ }^{2}$ Mestre em Engenharia, UFCG, UDESC (cleonesouza2@gmail.com)

${ }^{3}$ Doutorado em Engenharia, UFPEL (andreiabordinibrito@gmail.com)

${ }^{4}$ Designer, UFCG (fialhojr@gmail.com)
} 


\section{INTRODUÇÃO}

A sondagem vesical, ou cateterismo vesical, é o procedimento realizado com a introdução de uma sonda ou cateter na bexiga, pela uretra ou por via supra púbica, para a remoção da urina. As causas que levam uma pessoa à necessidade desse tipo de procedimento são variadas, pode ser devido a situações cirúrgicas (antes, durante e após a cirurgia), incontinência urinária, obstrução da saída da bexiga, entre outras (GOULD, 2009). A sonda utilizada pode ser de alívio - em casos de sondagem rápida, como drenar uma bexiga distendida, obter uma amostra de urina estéril, medir a urina residual ou esvaziar a bexiga antes da cirurgia; ou pode ser de demora - quando há necessidade de permanência da sonda por um período de dias ou mais, como em casos de drenagem vesical contínua ou alternada, introdução gota a gota de uma substância medicamentosa ou líquidos para irrigação, monitoramento da produção de urina dos pacientes, entre outros (ATKINSON \& MURRAY, 1989).

A duração da sondagem vesical é um importante fator de risco para o surgimento de Infecção no Trato Urinário (ITU) (STAMM; COUTINHO, 1999; AGÊNCIA NACIONAL DE VIGILÂNCIA SANITÁRIA [ANVISA] 2013). Segundo Lenz (2006, p. 84), a sondagem vesical de demora é diferente da de alívio, pois "[...] apresenta complicações sérias e temidas, como a infecção hospitalar, uma significativa morbidade, sepses e morte". Com o intuito de diminuir as complicações desse procedimento mais longo, a sonda de demora é utilizada dentro de um sistema fechado de drenagem urinária (Figura 1), que tem como finalidade vedar os pontos onde há maior risco de contaminações.

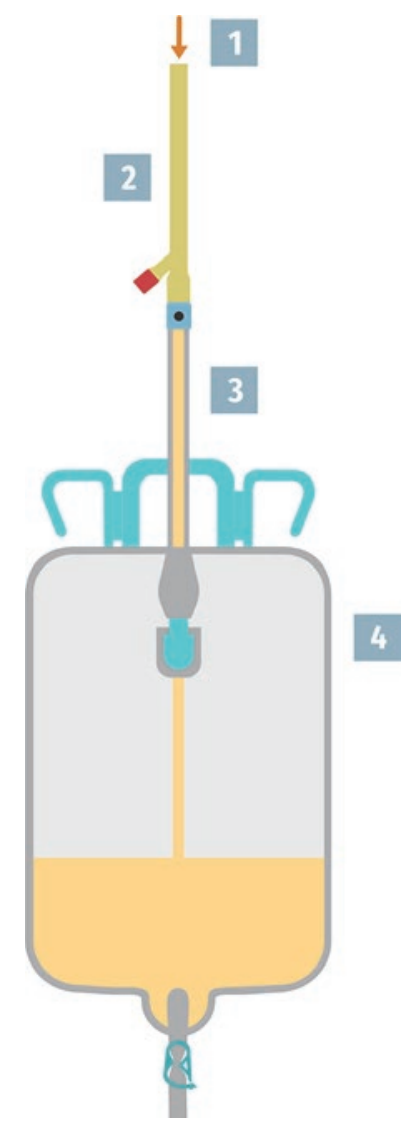

Figura 1 - Sistema Fechado de drenagem urinária Fonte: elaborado pelos autores 
O sistema fechado de drenagem urinária é composto pela sonda e pelo coletor de urina sistema fechado. A Figura 1 apresenta o funcionamento desse sistema: a urina armazenada na bexiga (1) migra para o sistema por meio da sonda (2) e segue pelo tubo extensor (3), ficando armazenada na bolsa coletora (4) até que a mesma seja esvaziada. A urina migra da sonda para a bolsa coletora devido à ação da gravidade método conhecido por drenagem direta.

Segundo Stamm e Coutinho (1999, p. 30), “O sistema coletor estéril fechado foi aperfeiçoado ao longo dos anos, sendo utilizado na maioria dos hospitais de hoje, mas a bacteriúria ocorre em média em 10 a 30\% dos pacientes cateterizados. Portanto, ele retarda mas não elimina o risco de infecção". Vieira (2009) esclarece que existem alguns fatores que predispõem o surgimento de ITU em pacientes com cateterismo vesical, como a sonda vesical desconectada do coletor de urina, a saída do coletor de urina tocando a superfície, expondo o usuário, o produto e o ambiente a alto risco de contaminação, o retorno da urina que se encontra na bolsa coletora ou no tubo extensor para a bexiga (refluxo), etc.

Embora não elimine totalmente o risco de infecção, o sistema fechado é uma das medidas utilizadas em procedimentos de sondagem vesical para prevenção de ITU (SOUZA; TIPPLE; BARBOSA; PEREIRA; BARRETO, 2007; LENZ, 2006). O sistema fechado caracteriza-se por vedar o sistema na junção da sonda com o tubo extensor do coletor de urina, que permite a introdução de uma solução sem a abertura do sistema, reduzindo assim o risco de infecção. Nesse contexto, uma empresa brasileira, que atua no setor de produtos médico-hospitalares e desenvolve vários tipos de coletores de urina, solicitou o redesenho de um coletor de urina sistema fechado ${ }^{1}$, com capacidade volumétrica de $2000 \mathrm{ml}$, utilizado especificamente em leitos de Unidades de Terapia Intensiva (UTIs) e Centros Cirúrgicos (CC).

Nas áreas onde o coletor de urina $X$ é utilizado, o risco de aquisição de infecção hospitalar (qualquer processo infeccioso adquirido no ambiente hospitalar) é particularmente elevado. Nas UTIs, os pacientes internados são mais susceptíveis a infecções hospitalares devido ao seu estado de deficiência imunológica, resultado também de procedimentos invasivos, como o cateterismo vesical. De acordo com Garibaldi (1987) apud Stamm e Coutinho (1999, p. 27), "entre os pacientes que são hospitalizados, mais de $10 \%$ são expostos provisoriamente à cateterização vesical de demora, o fator isolado mais importante que torna esses pacientes vulneráveis à infecção". Nos centros cirúrgicos, por sua vez, geralmente há grande número de inserção de cateteres, pois o controle da diurese durante cirurgias é uma das indicações mais comuns para a sondagem vesical de demora.

O objetivo deste estudo foi levantar e analisar informações acerca do usuário e do produto para definir os requisitos do projeto. A fase de preparação do processo de redesenho do coletor de urina $\mathrm{X}$ abrange desde a coleta de dados até as análises relacionadas ao operador, ao produto e seus concorrentes. $O$ resultado apresenta os requisitos para direcionar o redesenho do coletor de urina $X$, que busca proporcionar uma utilização prática ao operador, requerendo do mesmo o mínimo de manuseio e atendendo aos requisitos essenciais de higienização e de normas técnicas; dessa forma, o produto contribuirá para o controle dos fatores de risco que originam a in- 
cidência da ITU em pacientes hospitalizados.

\section{PROCEDIMENTOS METODOLÓGICOS}

A fundamentação teórica deste estudo abrangeu a literatura voltada à área de saúde, mais especificamente, artigos relacionados a doenças do sistema urinário e coletores de urina. A coleta de dados, realizada em campo, foi auxiliada pelo uso de técnicas etnográficas, como a prática da observação e conversação no contexto real (hospitais, enfermarias e UTIs) para observar os operadores e os aspectos relacionados ao manuseio e ao contexto de uso do produto. Também foram realizadas entrevistas informais com profissionais da área de saúde, que trabalham em hospitais na cidade de Campina Grande (médicos, enfermeiros, estudantes e técnicos de enfermagem), para coletar mais informações sobre a relação operador-produto e sanar dúvidas que surgiram durante a observação. O suporte teórico desta fase foram os autores Angrosino (2009) e Preece, Rogers e Sharp (2013).

Quanto ao produto, a empresa requerente do projeto forneceu o coletor de urina a ser redesenhado e coletores de marcas concorrentes para testes comparativos. O manuseio do produto foi estudado com os produtos concorrentes fornecidos e em vídeos online. Também foi realizada uma pesquisa em sites de compra de produtos para acessar as especificações técnicas e o funcionamento do produto. A pesquisa envolveu, ainda, o mercado local para conhecer os produtos com a mesma função, bem como para adquirir catálogos e fichas técnicas com informações auxiliares. Para complementar a coleta de dados, foi feita uma pesquisa de produtos tangíveis com funções afins em supermercados, como boias, colchões de ar e bolsas de gel.

Após a coleta, foram analisadas a relação operador-produto e a relação produto -ambiente, e para compreensão do produto e do processo de design, foram realizadas as análises denotativa e conotativa, sincrônica, estrutural e funcional, ergonômica, morfológica e das qualidades semânticas e estéticas. A etapa de análise teve como base o coletor de urina $X$, cedido pela empresa para essa função, cuja estrutura foi dividida em subsistemas. Por fim, os requisitos do projeto foram definidos após análise detalhada do produto $\mathrm{X}$, em função dos operadores, do produto e do ambiente onde está inserido. As técnicas utilizadas neste estudo foram documentação e análise fotográfica, desenhos esquemáticos e estruturais. Tanto na coleta, quanto na análise de dados, foram utilizados como apoio teórico da área de Design os trabalhos desenvolvidos por Bonsiepe (1984), Moraes (1994) e Lobach (2001) - quanto à metodologia projetual; e por lida (2003) e Dreyfuss (2005) - quanto à ergonomia do produto.

\section{ANÁLISE DO COLETOR DE URINA SISTEMA FECHADO}

\subsection{Perfil do usuário e do operador}

Durante a observação realizada em hospitais, pôde-se identificar dois tipos de personas que entram em contato com o coletor de urina. O primeiro tipo é designado como usuário - são pacientes de UTI ou Centro Cirúrgico que utilizam o produto para própria subsistência devido ao seu estado de saúde, porém não manipulam o produto por impossibilidade de movimentação. O outro tipo é denominado de operador 
- são os enfermeiros, técnicos e estudantes de enfermagem e médicos, profissionais da área de saúde que manipulam o produto para os usuários (pacientes). Considerando que o objetivo deste estudo está diretamente relacionado ao melhor manuseio do produto, os operadores são os indivíduos estudados nas análises. O grupo é definido por pessoas do gênero masculino ou feminino, em idade ativa, que possuem nível de escolaridade médio ou superior, atuam na área de saúde trabalhando em UTIs ou Centros Cirúrgicos.

\subsection{Relação operador-produto}

Conforme Löbach (2001), os produtos industriais podem exercer três tipos de funções: a prática, relacionada aos aspectos fisiológicos do uso; a estética, que diz respeito ao aspecto psicológico da percepção sensorial durante seu uso; e a simbólica, relacionada aos aspectos espirituais, psíquicos e sociais do uso.

Considerando que os médicos, enfermeiros e técnicos de enfermagem manipulam o produto durante o tratamento do paciente impossibilitado, percebe-se que a sua relação com o produto restringe-se à função prática, pois se trata de uma ferramenta de trabalho; assim, o operador não desenvolve relações com os aspectos estéticos ou simbólicos do mesmo. O operador realiza quatro operações relacionadas ao produto:

I) Colocação do coletor: durante o procedimento de cateterismo, o produto é retirado da embalagem e conectado à sonda. $O$ operador entra em contato com o produto esterilizado e ainda sem uso.

II) Aferição da urina armazenada no coletor: o operador apenas observa o produto e anota os valores referentes.

III) Esvaziamento do coletor: o operador aciona a válvula de saída (Figura 2).

IV) Retirada do coletor: acontece durante o procedimento de retirada do cateter, no qual o produto é descartado juntamente com a sonda. O operador entra em contato com o produto ao desconectá-lo da sonda e ao suspendê-lo para descarte.

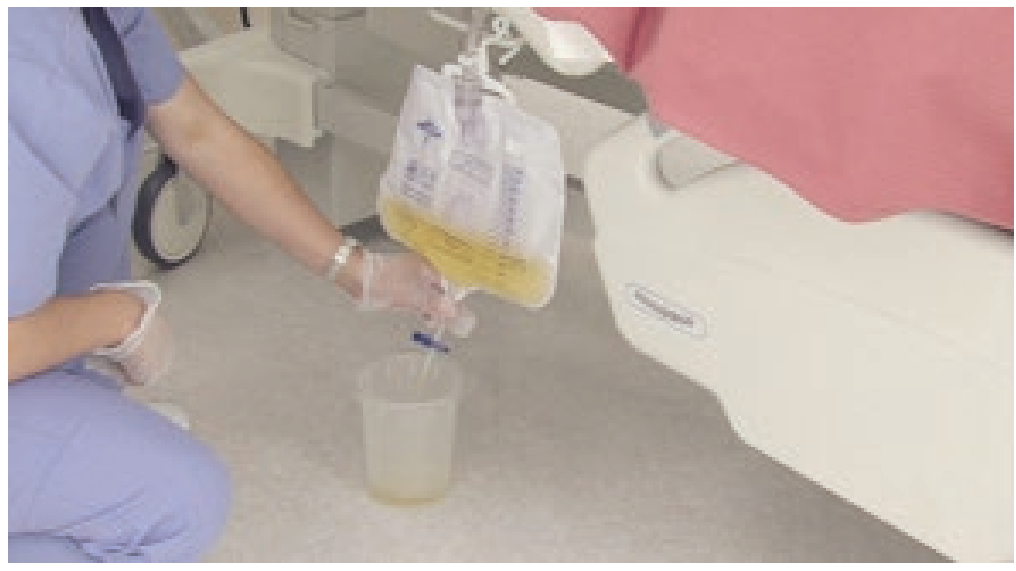

Figura 2 - Operadora esvaziando o coletor de urina

Fonte: elaborado pelos autores 


\subsection{Relação ambiente-produto}

O coletor de urina é fixado nas grade da cama e deve ficar suspenso abaixo do nível da bexiga do paciente e afastada do chão para facilitar a drenagem. Para elevar as grades é necessário fechar a pinça do tubo extensor para evitar o refluxo da urina (Souza et al., 2007).

Os ambientes de utilização do produto são: a Unidade de Terapia Intensiva (UTI), onde ficam internados os pacientes extremamente doentes que apresentam instabilidade clínica em gravidade potencial. É um ambiente de alta complexidade, reservado e único no ambiente hospitalar em que há monitorização completa durante 24 horas. E o Centro Cirúrgico (CC), que é um lugar preparado segundo um conjunto de requisitos que o tornam apto à prática cirúrgica por meio da ação de uma equipe integrada, onde são realizadas técnicas estéreis para garantir a segurança do paciente quanto ao controle de infecção.

\subsection{Análise Denotativa e Conotativa}

Estas análises têm como objetivo conhecer os significados denotativos e conotativos dos termos que designam o produto em questão. A denotação refere-se aos significados literários e não tem, necessariamente, relação com o contexto. Para realizar a análise denotativa, foram utilizadas as palavras bolsa e coletor, designações adotadas para o produto em questão (Figura 3).

\section{BOLSA}

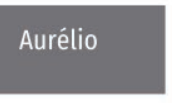

1. Cavidade que contém secreção ou outro fluido.

2. Bolsa de colostomia. Recipiente destinado a coletar matéria fecal eliminada através de colostomia.

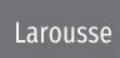

Saco de pequena dimensão, selado, para embalar produtos líquidos ou pastosos.

Michaelis
Recipiente de pano, couro, ou matéria plástica, cuja boca possui, às vezes, um sistema qualquer de fechamento, como ziper, botões etc.

\section{COLETOR}

1. Que colige, compila, reúne.

2. Diz-se de cano principal de esgoto, ou de águas pluviais, no qual se encontram os canais secundários.

Todo recipiente em que se juntam coisas.

Aparelho ou recipiente destinado a recolher alguma substância.

Figura 3 - Análises Denotativa

Fonte: elaborado pelos autores

A conotação refere-se ao significado que algo vai adquirindo ao longo do tempo, logo, está diretamente ligado ao contexto. Para a análise conotativa (Figura 4), considerou-se o termo coletor de urina, inserido no contexto do problema estudado. 


\section{COLETOR DE URINA}

Medical
Line

Danbury

Hospital

Produto que permite avaliar com precisão o volume drenado, extensão distal com conector de três vias acoplado a uma bolsa de $400 \mathrm{ml}$ com sistema antirrefluxo e tampa para fechamento do sistema. Devido às conexões eficientes e a configuração desenvolvida, diminui de forma substancial os riscos de infecção do trato urinário. Fonte: www.medicalline.com.br

Saco de pequena dimensão, selado, para embalar produtos líquidos ou pastosos. Fonte: www.danburyhospital.org

Figura 4 - Análise Conotativa Fonte: elaborado pelos autores

\subsection{Análise Sincrônica}

A análise sincrônica possibilita conhecer melhor o mercado onde o produto está inserido, tomando como referencial comparativo os produtos concorrentes disponíveis (Bonsiepe, 1984). A Figura 5 apresenta os produtos selecionados para a análise sincrônica - o coletor de urina X (produto 1 ) e seis coletores concorrentes selecionados, sendo os produtos 3, 4, 5 e 7 fornecidos pela empresa X, e as imagens dos demais encontradas na Internet durante o levantamento de dados. Todos os coletores são utilizados em leitos de hospitais e possuem capacidade para armazenar $2000 \mathrm{ml}$ de urina. Os critérios estabelecidos para comparação dos produtos foram material, dimensões da bolsa e preço.

\section{ANÁLISE SINCRÔNICA}

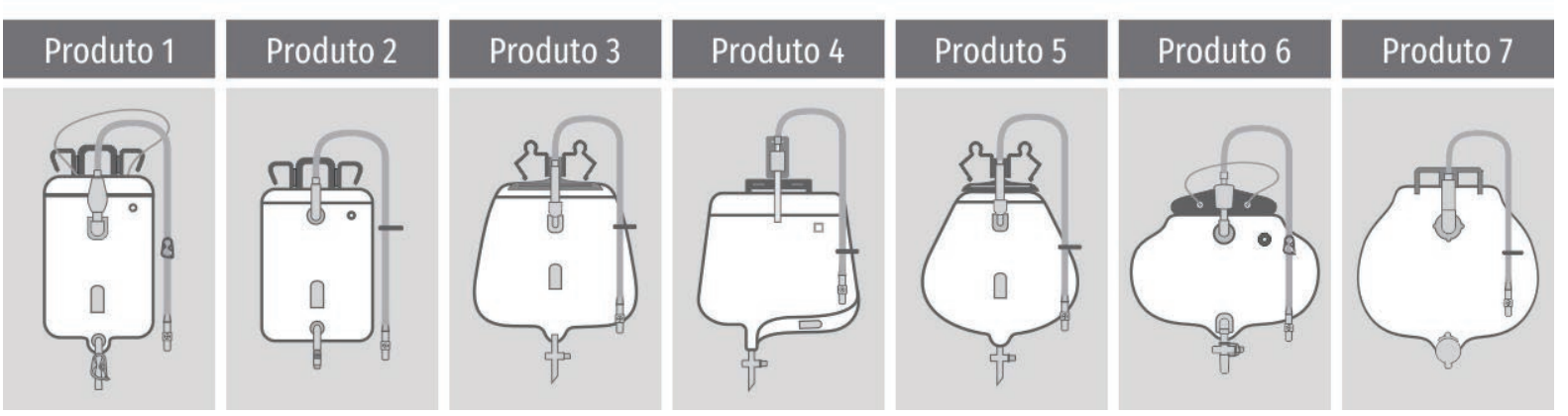

Figura 5 - Análise Sincrônica

Fonte: elaborado pelos autores

Quanto à estrutura, os produtos apresentaram pontos semelhantes: orientação vertical ou horizontal, com comprimento em média de $30 \mathrm{~cm}$, peso leve, o material presente em todos os coletores é o PVC, tanto rígido quanto flexível. Os coletores 3, 4, 5 e 7 são produzidos no exterior e comercializados no Brasil por preços semelhantes aos demais que são nacionais. Em geral, os coletores possuem os mesmos subsistemas, sendo alguns com variação, como uma pinça para prender no lençol presente nos coletores 2, 5, 6 e 7 . 


\subsection{Análise Estrutural e Funcional}

$\mathrm{Na}$ análise estrutural compreende-se os aspectos relacionados à estrutura do produto, seus subsistemas, materiais, princípios de montagem, componentes de fixação, processos de fabricação, entre outros (Bonsiepe, 1984). Para a realização das análises estrutural e funcional, o coletor de urina foi dividido em quatro subistemas principais: 1) conector de sonda, (2) tubo extensor, (3) bolsa e (4) conector de saída; e dez subsubsistemas, conforme indicado na Figura 6.

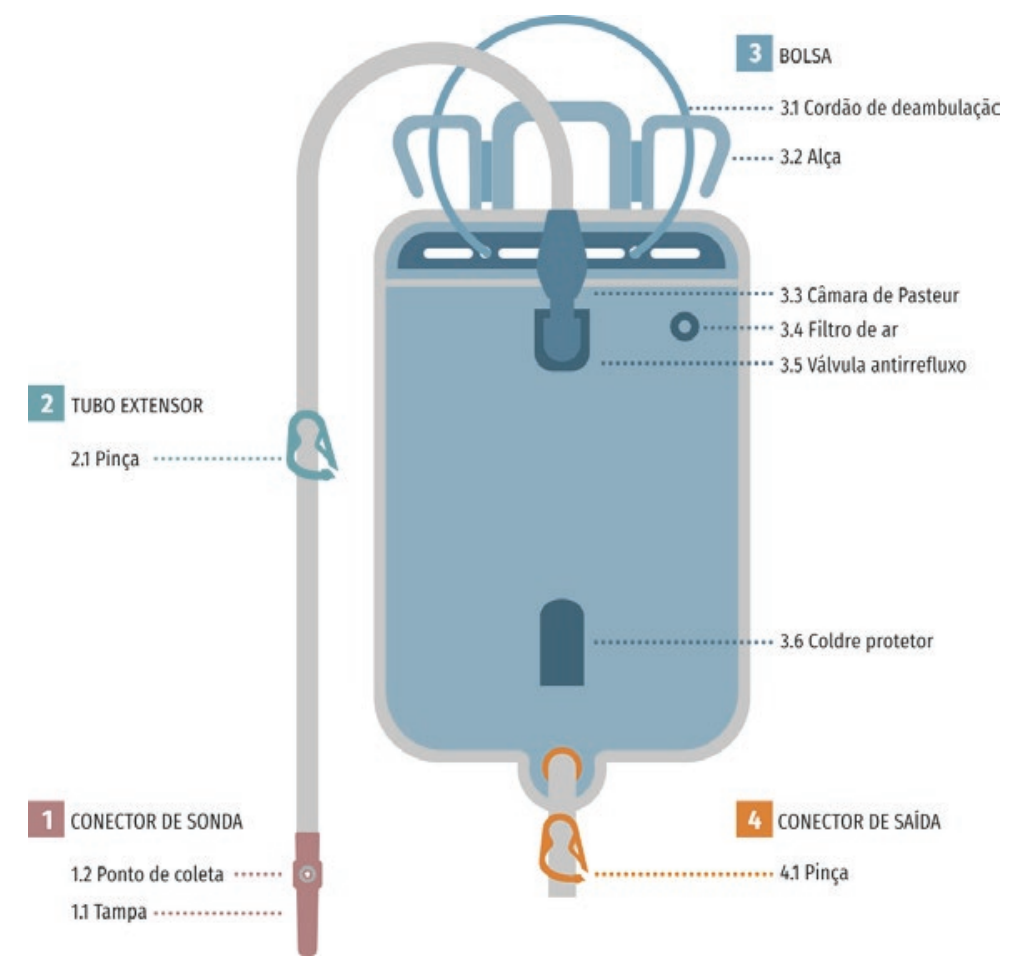

Figura 6 - Subsistemas e subsubsistemas do coletor de urina $\mathrm{X}$ Fonte: elaborado pelos autores

A análise funcional está relacionada aos sistemas funcionais dos produtos e buscou compreender as macro e microfunções desempenhadas pelos subsistemas e subsubsistemas do coletor de urina X (Figura 6). A função principal do produto é armazenar a urina expelida pelo corpo do paciente que se encontra em UTI ou CC. A função secundária é possibilitar a coleta e aferição da urina.

O conector de sonda (1) é o primeiro subsistema, responsável por conectar a sonda (inserida no corpo do paciente) ao coletor de urina, vedando a estrutura, o que caracteriza o sistema fechado desse tipo de coleta de urina. O subsistema é composto pela tampa (1.1), que protege o sistema após a esterilização e antes do uso; e pelo ponto de coleta (1.1) que é o acesso para coleta de material asséptico para exames.

O segundo susbsitema é o tubo extensor (2) que tem como função conduzir a urina à bolsa; sua extensão também possibilita a movimentação da bolsa coletora. 0 tubo extensor tem um subsubsistema - a pinça (2.1), que impede o refluxo da urina em casos de manipulação ou movimentação do paciente ou da bolsa; também pode ser utilizada para desobstruir o tubo extensor ou reeducar a bexiga (com abertura e fechamento controlados em casos específicos, sob determinação médica). 
A bolsa de urina (3) é o terceiro subsistema, responsável pela função principal do produto: armazenar a urina. A bolsa é composta por seis subsubsistemas. A alça (3.1) tem a função de suspender o coletor, deixando-o fixo no local adequado; o (3.2) cordão de deambulação é utilizado para suspender o produto durante o transporte; a câmara de Pasteur (3.3) evita a ascensão de bactérias que se desenvolvem na bolsa e também possibilita a ordenha para desmanche de coágulos. A válvula antirrefluxo (3.4) impede o refluxo de urina se a bolsa for colocada em posição diferente da indicada - pode acontecer durante a movimentação do paciente, por exemplo. O filtro de ar (3.5) é responsável por retira o ar que entra na bolsa, proveniente do corpo humano; e o coldre protetor (3.6) isola o conector de saída do ambiente onde está localizado.

O quarto subsistema é o conector de saída (4), que conduz a urina para o exterior da bolsa, esvaziando o produto. Possui um subsubistema, a pinça (4.1), responsável pela abertura da bolsa para esvaziá-la.

Os principais materiais utilizados no produto são PVC e PP; em menor escala, utiliza-se Borracha (Laprene) e um combinado de Resina, DOP, Stavin e Soyflex que constituem a câmara de Pasteur. Outro material utilizado compõe o filtro de ar, no entanto, não foi especificado, pois se trata de um componente terceirizado pela empresa. Os processos de fabricação utilizados no coletor $X$ são injeção, extrusão, emulsão e radiofrequência; e a junção entre as partes do produto é feitas com radiofrequência, encaixe ou cola.

\subsection{Análise Ergonômica}

A análise ergonômica compreende a análise de aspectos relacionados à segurança, ao conforto e à usabilidade do produto a fim de identificar as dificuldades dos operadores e propor melhorias para supri-las. O enfoque desta análise foi sistemático e sistêmico, seguindo a proposta de Moraes (1994) - sistemático pelas características metódicas da análise e sistêmico porque se refere à lógica de um sistema como um todo. A análise foi composta pelas etapas: ordenação hierárquica das partes do produto (Figura 7), descrição da tarefa, medidas antropométricas e o estudo de pegas e manejos.

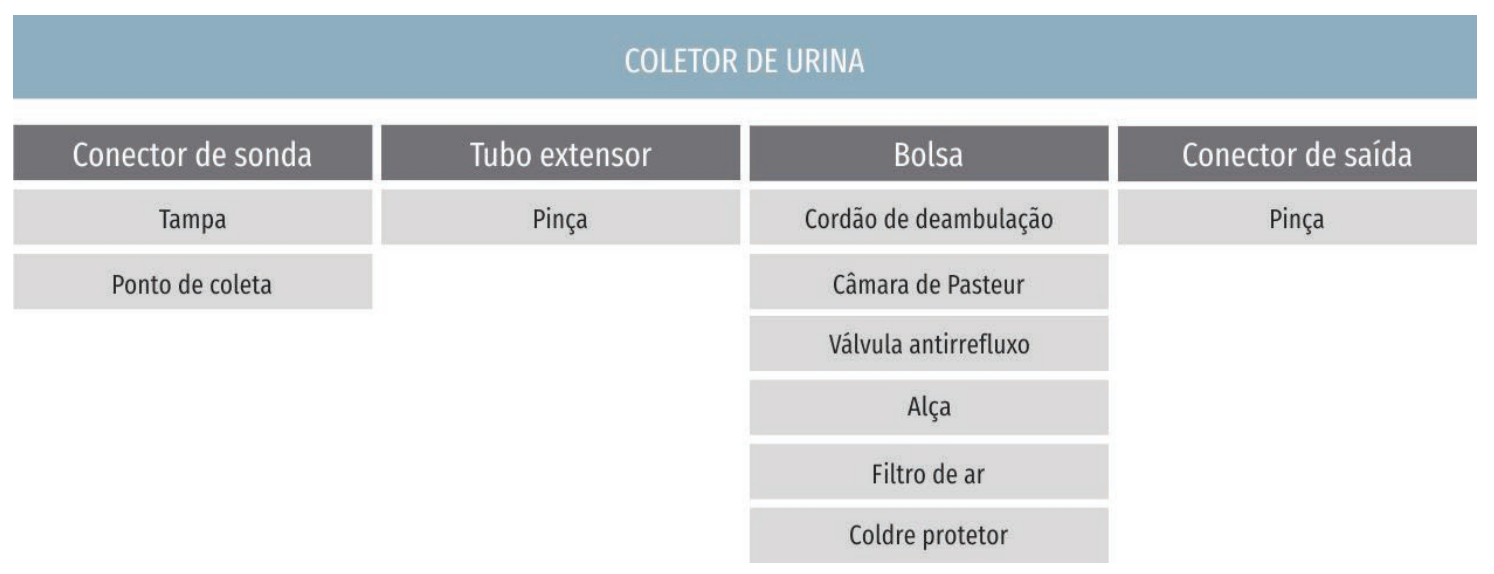

Figura 7 - Ordenação hierárquica das partes do produto Fonte: elaborado pelos autores 
A tarefa é definida por lida (2003) como um conjunto de ações humanas que possibilita que um sistema de atinja seu objetivo. Durante a análise da tarefa é possível detectar os problemas que o operador encontra ao manipular o produto e, dessa forma, introduzir as modificações necessárias para que ele realize a tarefa com conforto e segurança. Esta etapa teve como base a tarefa realizada por uma enfermeira durante o seu horário de trabalho na UTI do Hospital Universitário Alcides Carneiro - HUAC, em Campina Grande. A Figura 8 apresenta as informações gerais referentes à tarefa.

\begin{tabular}{|c|c|c|c|}
\hline Objetivo & Operadores & Condições operacionais & Condições organizacionais \\
\hline $\begin{array}{l}\text { Utilização do coletor com a } \\
\text { finalidade de armazenar a } \\
\text { urina do paciente para aferição. }\end{array}$ & $\begin{array}{l}\text { Médicos, enfermeiros, } \\
\text { técnicos e estudantes de } \\
\text { enfermagem que trabalham } \\
\text { em UTIs ou CC. }\end{array}$ & $\begin{array}{l}\text { Serão consideradas quatro } \\
\text { operações: i) colocaçãa do } \\
\text { coletor (em pé); ii) aferição da } \\
\text { urina agachado); iii) esvaziamento } \\
\text { da bolsa (agachado) e iv) retirada } \\
\text { do coletor (em pé). As ações são } \\
\text { realizados com luvas. }\end{array}$ & $\begin{array}{l}\text { Os profissionais que mais } \\
\text { manuseiam o produto são } \\
\text { técnicos em enfermagem. Os } \\
\text { enfermeiros fazem o } \\
\text { acompanhamento periódico e } \\
\text { os médicos manuseiam o } \\
\text { produto esporadicamente. }\end{array}$ \\
\hline
\end{tabular}

Figura 8 - Descrição da tarefa

Fonte: elaborado pelos autores

Outro aspecto da análise ergonômica é a antropometria - área da Ergonomia que trata das medidas físicas do corpo humano (lida, 2003) e possibilita a adequação dos objetos e locais aos usuários e, nesse caso, aos operadores também. A análise da tarefa identificou as ações que os operadores realizam com o coletor de urina envolvem o uso das mãos. Dessa forma, considerando a abrangência do público-alvo, foram utilizadas as medidas antropométricas das mãos de homens de percentil 99, que abrange $99 \%$ da população, conforme pode ser encontrado em Dreyfuss (2005), para analisar as dimensões das partes do produto e, se necessário, redimensioná-las.

A manipulação do produto ocorre por meio de pegas e manejos. lida (2003) define pega como sendo o engate entre a mão da pessoa e o produto, e manejo é a forma que ocorre esse engate. Existem dois tipos básicos de manejo: manejo fino (executado com as pontas dos dedos, como ligar o interruptor) e manejo grosseiro (realizado com o centro da mão, como mudar a marcha do carro). O desenho do manejo pode ser geométrico - semelhante a uma figura geométrica regular, ou antropomorfo - que possui superfície anatômica. O estudo de pegas e manejos abrangeu as principais ações que o operador realiza ao manipulá-lo diariamente (Figura 9). Também foram analisadas uma variação da pinça e uma variação do conector de saída². 

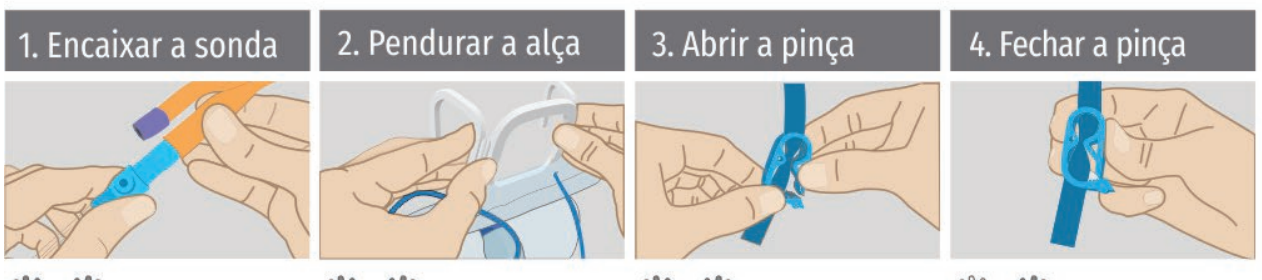

5. Encaixar o conector
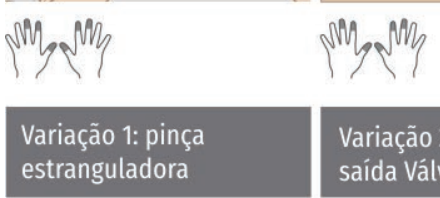

masm
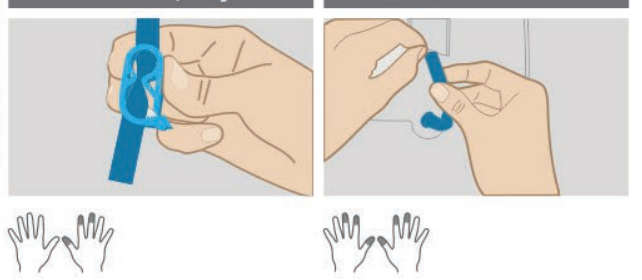

Variação 1: pinça

Variação 2: conector de saida Válvula T
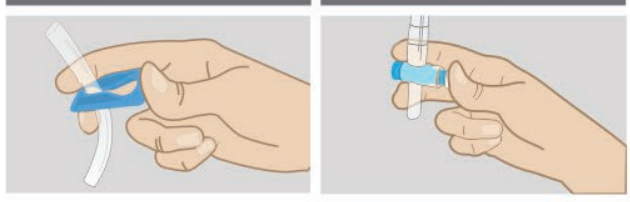

shy

angang

Figura 9 - Pegas e manejos do coletor de urina Fonte: elaborado pelos autores

\subsection{Análise Morfológica}

Os sete coletores especificados na análise sincrônica apresentam semelhanças relacionadas aos princípios construtivos do subsistema 3 (bolsa). Assim, os produtos foram agrupados conforme a semelhança que apresentaram na configuração geral da bolsa (Figura 10).

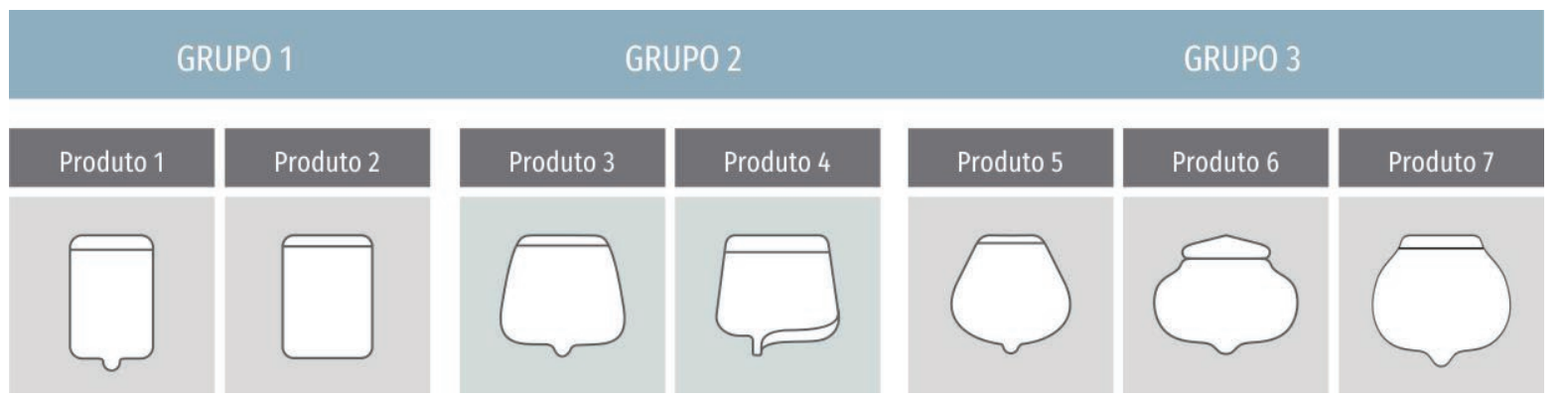

Figura 10 - Análise morfológica dos coletores de urina Fonte: elaborado pelos autores

Os grupos apresentam em comum elementos formais que transmitem a ideia de estabilidade, são construídos a partir de elementos geométricos e a configuração é simétrica, com exceção do coletor 4 que apresenta leve assimetria. 0 grupo 1 tem como base um retângulo vertical com bordas arredondadas. No grupo 2, os coletores 3 e 4 foram construídos a partir de um quadrado, cujas bordas foram arredondadas, e a parte inferior é maior que a superior. No grupo 3, os coletores 5,6 e 7 se diferenciam dos demais por possuírem formas mais orgânicas. 


\subsection{Análise das qualidades estéticas e semânticas}

A cor é um importante elemento configurativo de forma que, segundo Lobach (2001), é indicada para atingir a psique do operador por meio de suas inúmeras formas de aplicação. Os coletores analisados possuem a frente da bolsa transparente para possibilitar a aferição da urina. O azul, o verde e o branco (cor dominante) são mais utilizados nos coletores.

A maioria das superfícies do produto são lisas e brilhantes. A bolsa é lisa e fosca. Em alguns coletores há presença de partes com texturas que sugerem ao operador movimento e ajudam no manuseio, como o conector de saída. Algumas partes de encaixe contém nervuras ou estímulo auditivo (clique) para assegurar que a ação foi efetivada, comunicando segurança ao operador.

A forma dos subsistemas do produto é uma característica que sugere ao operador como utilizá-lo. Fazendo uma leitura do produto na direção vertical, o primeiro subsistema é o conector de sonda (1), que possui formato cilíndrico e nervuras; apresenta uma das extremidades abertas, característica que faz o operador pensar que esta peça funciona como conector e será encaixada em outra com mesmo formato; o tubo extensor (2) também possui formato cilíndrico e diâmetro reduzido, indicando ao operador veículo de passagem até a bolsa (3), que é a maior parte do produto e tem espaço disponível para armazenar a urina. O conector de saída (4) é a última parte do coletor e, portanto, a saída da urina.

\section{REQUISITOS PARA O REDESENHO DO COLETOR DE URINA SIS- TEMA FECHADO}

As análises foram realizadas com base nas observações de como o produto é utilizado no seu contexto e, a partir disso, foram elaborados os requisitos que vão direcionar a próxima etapa do projeto de redesenho do coletor de urina $\mathrm{X}$ - a geração de conceitos. Além de abranger os resultados das análises, os requisitos também consideram as solicitações da empresa requerente, que estão especificados na sequência desta seção. A Figura 11 apresenta os requisitos elaborados ao fim deste estudo. 
REQUISITOS DO PROJETO

\begin{tabular}{l} 
Estruturais \\
Manter os subsistemas requisitados pela empresa \\
As dimensões (altura e largura) não devem ultrapassar as dimensões dos coletores concorrentes \\
\hline Ergonômicos Funcionais e de Uso \\
\hline A estrutura deve facilitar o processo de aferição da urina \\
A estrutura deve proporcionar o esvaziamento total da bolsa \\
Utilizar a pinça que possibilitou melhor manuseio na análise de pegas e manejos \\
Empregar cores como indicativo de uso/manuseio \\
\hline Materiais e processos de fabricação \\
\hline Manter o material utilizado atualmente pela empresa $X$ \\
Utilizar os processos de fabricação disponiveis na empresa X \\
\hline Estéticos e MorfológicoS \\
\hline A bolsa coletora deve transmitir estabilidade \\
Possuir unidade e coerência formal \\
Apresentar cores e texturas que transmitam sensação de limpeza \\
\hline Segurança \\
Utilizar o conector de sonda adaptado às exigências mais atuais da ANvISA \\
Obedecer as exigências da ANvISA quanto às cores de determinados subsistemas
\end{tabular}

Figura 11 - Requisitos para o redesenho do coletor de urina $\mathrm{X}$ Fonte: elaborado pelos autores

As análises denotativa e conotativa possibilitaram conhecer os significados dos termos relacionados ao tema - a denotação indicou que os termos analisados coletor e bolsa, embora não possuam correlação com o contexto do projeto, ou seja, não fazem referência ao sistema urinário ou hospitalar, apresentam a mesma função de armazenar coisas. A análise conotativa mostrou os significados adquiridos do termo coletor de urina, que está relacionado ao projeto em questão. A análise Sincrônica reuniu sete coletores que se mostraram semelhantes em termos de capacidade volumétrica, dimensões, materiais utilizados e preço. A empresa requisitou que as dimensões não ultrapassem as dos produtos concorrentes.

As análises estrutural e funcional do coletor de urina $\mathrm{X}$ foram realizadas a partir da divisão do produto em subsistemas. Em relação à estrutura, a orientação vertical e as extremidades do produto identificam a sua utilização; os subsistemas e subsubsistemas do produto apresentaram-se adequados entre si, uma vez que as partes são bem fixadas, atendendo às necessidades relativas ao fechamento do sistema. Os materiais utilizados no produto atendem à resolução RDC/ANVISA n 593 e serão mantidos e os processos de fabricação devem ser os correntes, ainda que possa haver alterações na ordem do processo.

A análise funcional demonstrou que o produto realiza as funções primária e secundária, no entanto, existe alguns pontos em relação à forma que atrapalham o 
desempenho funcional e de usabilidade do produto. A forma retangular da bolsa e a posição do conector de saída dificultam o total esvaziamento da bolsa, por outro lado, a forma retangular proporciona mais estabilidade à bolsa quando ela está cheia. Dessa forma, recomenda-se a alteração da forma considerando os aspectos citados a fim de que a bolsa não acumule urina e ao mesmo tempo continue estável, pois a estabilidade auxilia a mantê-la na posição adequada e facilita a aferição da urina. Também é aconselhável utilizar o conector de saída denominado válvula T, cuja anatomia facilita a vazão da urina da bolsa. A válvula T já é produzida pela empresa e utilizada em outros coletores. Além disso, na análise ergonômica essa válvula mostrou-se mais confortável durante o manuseio em comparação com a pinça estranguladora.

Durante a análise da tarefa, foi possível perceber que o operador deve agacharse para checar as características da urina armazenada no coletor de urina $\mathrm{X}$, que fica suspenso na cama. Essa atividade não necessita que o operador segure o produto, no entanto, à medida que a urina entra na bolsa, a estrutura fica dilatada e se deforma, dificultando o processo de aferição e fazendo com que o operador tenha que segurar e rotacionar o produto para realizar a tarefa. O ideal é que haja o mínimo de contato do produto com o operador ou com o ambiente para evitar o risco de contaminação. O estudo de pegas e manejos também revelou que o operador utiliza as duas mãos para encaixar o conector de saída no coldre protetor, assim, recomenda-se a utilização de um coldre protetor de PVC rígido acoplado diretamente ao conector de saída, que requer o uso de apenas uma mão para manuseá-lo.

A análise morfológica e a análise das qualidades estéticas e semânticas resultaram em requisitos estéticos e morfológicos relacionados à forma, cores, texturas e superfícies, sempre em referência à funcionalidade e usabilidade do produto. Quanto às cores, recomenda-se que sejam utilizados o branco como cor dominante e cores frias nas partes do produto que indicam uma ação. Em termos de simbologia, essas cores transmitem sensação de limpeza. Funcionalmente, característica importante para este tipo de produto que é utilizado em ambientes hospitalares, trata de líquidos expelidos pelo corpo humano e permanece com o usuário durante certo período. As cores claras também permitem melhor visualização e facilitam a higienização do produto. Recomenda-se também que o coletor mantenha a transparência na parte frontal da bolsa coletora, visto que o monitoramento das características da urina são de extrema importância para a recuperação daqueles que a utilizam. Similarmente, ocorre com o tubo extensor que, por ser transparente, possibilita a visualização da urina.

A forma do coletor $X$ deve atender às necessidades já comentadas, transformando-se em um produto mais amigável e anatômico e, ao mesmo tempo, proporcionando melhor usabilidade e funcionalidade do produto. Indica-se a permanência das superfícies lisas, das texturas que auxiliam nos encaixes onde há nervuras, e do estímulo auditivo que afirma a ação efetivada na tampa do tubo extensor na tampa do tubo extensor.

\section{CONSIDERAÇÕES FINAIS}

Este estudo apresentou a fase de preparação do processo de redesenho do coletor de urina sistema fechado $\mathrm{X}$, que abrangeu a coleta e análise de dados fundamenta- 
das no usuário, no produto e no ambiente de utilização do produto, e apresentou como resultado os requisitos para a próxima fase do processo de redesenho do produto.

A colocação e retirada do coletor de urina envolvem o procedimento de sondagem vesical de demora (introdução da sonda ou cateter na bexiga), pois o coletor de urina e a sonda constituem o sistema fechado de drenagem urinária. O procedimento de sondagem vesical é mais propenso ao desenvolvimento de ITUs devido ao tempo extenso em que a sonda fica inserida no paciente internado. Assim, a utilização do coletor de urina tem relação direta com o uso da sonda de demora e, por consequência, com os riscos de infecção aos quais os pacientes estão sujeitos. Dessa forma, buscou-se apontar direcionamentos para que as próximas etapas do processo de design sejam realizadas priorizando a segurança e o conforto, tanto daqueles que utilizam como dos que manipulam o produto.

Foram encontradas na literatura medidas preventivas que devem ser adotadas no procedimento de sondagem vesical (ou cateterismo) para minimizar o alto risco de infecção. $O$ coletor de urina $X$ foi analisado tendo em vista tais medidas preventivas, já que a manipulação do produto exerce papel fundamental no procedimento de como um todo e, dessa forma, também pode auxiliar na prevenção e na diminuição da incidência de infecção hospitalar, durante as ações realizadas pelos operadores. A empresa requerente do projeto segue, também, um protocolo de avaliação dos produtos durante todo o processo de fabricação, e atende às determinações da resolução RDC/ANVISA n 593.

Durante a pesquisa de campo, as entrevistas informais realizadas mostraram que, em relação ao manuseio do coletor de urina, os operadores relataram situações que tendem a ser ideais, isto é, fizeram descrições de uso do produto que, em parte, fogem da realidade diária. Nesse aspecto reside a importância da entrevista informal e da observação, realizadas em diferentes momentos no contexto onde o produto é utilizado, que possibilitam a percepção da diferença entre o ideal relatado e o real praticado. Durante as entrevistas, também foi possível esclarecer, de maneira indireta, o porquê de algumas ocorrências observadas.

As limitações deste estudo estão relacionadas às solicitações da empresa X que, pautadas na mínima interferência no processo produtivo e nos recursos da empresa, solicitou o redesenho, especificamente, da bolsa de urina, enquanto as demais partes do produto devem ser compostas por componentes já produzidos pela empresa e utilizados na sua linha de coletores. A empresa produz dois tipos de conectores de saída, por exemplo, ambos foram estudados e, a partir dos resultados das análises, selecionados para compor o coletor de urina sistema fechado. Isto é, o conector que se apresentou mais apropriado em relação ao usuário, ao produto e ao ambiente foi escolhido para compor o produto.

Outro aspecto limitante é sobre a própria natureza do coletor de urina que, por ser um produto voltado à saúde humana e por sua utilização envolver um alto risco de infecção hospitalar, tem como principal função a prática. Além disso, o coletor de urina $\mathrm{X}$ é utilizado em hospitais e, conforme esclarecido pela engenheira de produção da empresa, é adquirido por meio de licitação - o produto é vendido conforme a proposta ou a oferta de menor preço. Por essas razões, e também buscando a mínima alteração nos custos da produção, a empresa prioriza as questões relacionadas à 
função prática do produto em detrimento das funções estética e simbólica.

Entretanto, é importante ressaltar a importância da contribuição do design na melhoria dos aspectos relacionados às funções estética e simbólica do produto, uma vez que é possível, além de atender as necessidades de segurança e conforto durante a utilização, melhorar as relações afetivas que o usuário desenvolve com produtos desse tipo, utilizados para suprir uma deficiência imposta pelo estado de saúde do indivíduo.

\section{REFERÊNCIAS}

ANGROSINO, M. Etnografia e Observação Participante. [Coleção Pesquisa Qualitativa]. Porto Alegre: Artmed, 2009.

Agência Nacional de Vigilância Sanitária. Medidas de Prevenção de Infecção Relacionada à Assistência à Saúde, 2013. Disponível em: <http://portal.anvisa.gov.br/>. Acesso em: 27 mai. 2016.

ATHIKSON, L. \& Murray, M. Fundamentos de Enfermagem. Introdução ao Processo de Enfermagem. Rio de Janeiro: Guanabara, 1989.

BONSIEPE, G. Metodologia experimental - Desenho Industrial. Brasília: CNPQ/ Coordenação Editorial, 1984.

DREYFUSS, H. As Medidas do Homem e da Mulher. Porto Alegre: Bookman, 2005. GOULD, C., UMSCHEID, C., AGARWAL, R., KUNTZM, G., PEGUES, D. The Healthcare Infection Control Practices Advisory Committee, 2009. Disponível em: <http:// www20.anvisa. gov.br/>. Acesso em: 27 mai. 2016.

IIDA, I. Ergonomia: Projeto e Produção. São Paulo: Edgard Blücher, 1990.

LENZ, L. Cateterismo vesical: cuidados, complicações e medidas preventivas. Arquivos Catarinenses de Medicina, v. 35, n. 1, 82-91, 2006.

LOBACH, B. Design Industrial. São Paulo: Blucher, 2001.

MORAES, A. Human-computer interaction: navegando ou dialogando; engenharia de software, ergonomia, comunicação visual. In: $2^{\circ}$ ENCONTRO CARIOCA DE ERGONOMIA, 1994. Anais do $2^{\circ}$ Encontro Carioca de Ergonomia, Rio de Janeiro, p. 85-96.

PREECE, J., ROGERS, Y., SHARP, H. Design de Interação: Além da interação homemcomputador. Porto Alegre: Bookman, 2013.

SOUZA, A., TIPPLE, A., BARBOSA, J., PEREIRA, M., BARRETO, R. Cateterismo urinário: conhecimento e adesão ao controle de infecção pelos profissionais de enfermagem. Revista Eletrônica de Enfermagem, v. 9, n. 3, p. 724-735, 2007. 
STAMM, A., COUTINHO, M. Infecção do trato urinário relacionada ao cateter vesical de demora: incidência e fatores de risco. Revista da Associação Médica Brasileira, v. 45, n. 1, p. 27-33, 1999.

VIEIRA, F. Ações de enfermagem para prevenção de infecção do trato urinário relacionada ao cateter vesical de demora. Einstein, v. 7, n. 3, p. 372-375, 2009. 